\title{
Acute Pancreatitis Secondary to the Drug Tamoxifen: About a New Clinical Case
}

\author{
F. Aboutarik ${ }^{1 *}$, S. Roudi ${ }^{1}$, J. Rizkou ${ }^{1}$, A. Ait Errami ${ }^{1}$, Z. Samlani ${ }^{1}$, K. Krati ${ }^{1}$, S. Oubaha ${ }^{2}$
}

${ }^{1}$ Department of Hepato-Gastro-Enterology, Arrazi hospital, Mohammed VI University Hospital Center, Marrakech 40000, Morocco

${ }^{2}$ Department of Physiology, Faculty of Medicine, Cadi Ayyad University, Marrakech 40000, Morocco

DOI: $10.36347 /$ sjmcr.2020.v08i08.012

| Received: 12.08.2020 | Accepted: 20.08.2020 | Published: 26.08.2020

*Corresponding author: Fatimaezzahra Aboutarik

Abstract

Case Report

Drug-induced acute pancreatitis is a rare pathology with a pathophysiology that is poorly understood. The diagnosis is made after eliminating the other classic causes of pancreatitis. The treatment behind the acute pancreatitis should be stopped permanently. We report a new observation of a case with acute drug-induced pancreatitis after a prolonged use of tamoxifen.

Keywords: Drug-induced acute pancreatitis - Hypertriglyceridemia - Tamoxifen.

Copyright @ 2020: This is an open-access article distributed under the terms of the Creative Commons Attribution license which permits unrestricted use, distribution, and reproduction in any medium for non-commercial use (NonCommercial, or CC-BY-NC) provided the original author and source are credited.

\section{INTRODUCTION}

Acute drug-induced pancreatitis is a rare condition $[1,2]$, defined by the occurrence of a flare-up of pancreatitis after the administration of a drug while eliminating other classic causes [3]. Several drugs have been implicated in the occurrence of drug-induced pancreatitis, cases of acute pancreatitis have been reported under treatment with tamoxifen, which acts by inhibiting the growth of tumor cells by competitive estrogen antagonism. It was developed for the treatment of breast cancer in the 1970s. It was the first antiestrogen available and, for almost 30 years, the gold standard until the arrival of aromatase inhibitors for postmenopausal patients [1].

We report a new case of hypertriglyceridemia and acute drug-induced pancreatitis following prolonged use of tamoxifen.

\section{CASE RePORT}

We report the clinical case of a 42-year-old patient who was treated for a cancer of the left breast for 6 years, for which she underwent a left mastectomy followed by concomitant radio chemotherapy and then treated with tamoxifen at a dose of $20 \mathrm{mg} / \mathrm{d}$, the exposure time was 9 months. The patient was admitted to our department for epigastralgia with dorsal irradiation occurring after a copious dinner, associated with bilious vomiting. The history showed no evidence of known dyslipidemia or alcohol consumption. The clinical examination objectified an apyretic patient, stable on the hemodynamic and respiratory conditions with an epigastric tenderness. The blood tests noted a lipasemia level at $2907 \mathrm{IU} / \mathrm{L}$ (> 3N), thus the diagnosis of acute pancreatitis was concluded. Regarding the rest of the biological assessment, hypertriglyceridemia was objectified at $950 \mathrm{mg}$ dl while the blood count, blood ionogram, calcium level and hepatic tests were normal. As part of the assessment of this case, there were no signs of clinical or laboratory severity according to the SIRS score, and abdominal CT had found acute stage C Balthazar pancreatitis (Image-1). The gallbladder was alithiasis and the intra and extra hepatic bile ducts were not dilated. The drug origin was then suspected justifying the interruption of treatment.

The management of acute pancreatitis was based on resting the digestive tract, rehydration, analgesics, anti-ulcer prevention by a proton pump inhibitor, with a good clinical and biological evolution. Other tests were made to eliminate the other causes of acute pancreatitis such as an auto-immune test was requested, in particular for the dosage of IGg4 which returned negative, the diagnosis of acute pancreatitis secondary to tamoxifen was then retained. The evolution was marked by a marked clinical improvement (disappearance of pain), and biological improvement (normalization of lipasemia and triglyceridemia) after stopping the treatment in question, a diet and lipid-lowering treatment. After that, the patient was referred to his attending oncologist to discuss changing the treatment. 


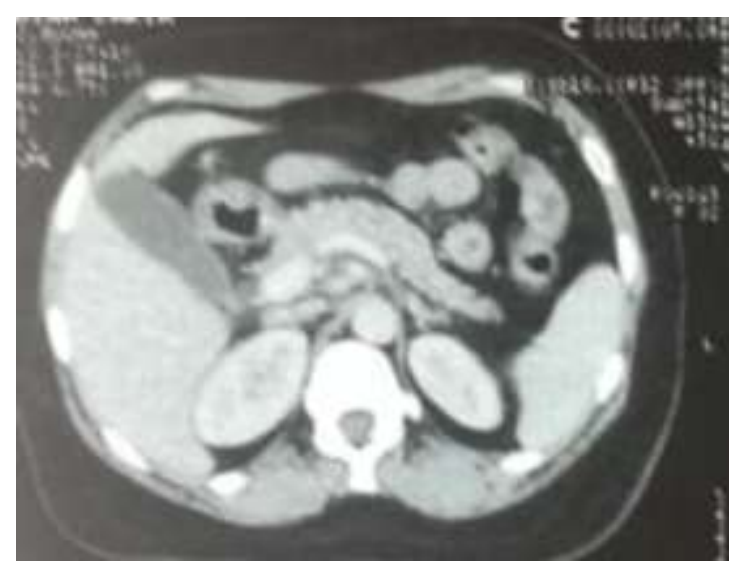

Image-1: Acute stage $C$ Balthazar pancreatitis

\section{DISCUSSION}

Acute drug-induced pancreatitis is a rare condition. Its prevalence varies from 1 to $2 \%$ depending on the study $[4,5]$. It is defined by the occurrence of an outbreak of pancreatitis after the introduction of a drug or after an increase in its doses, and this in the absence of a classic cause of pancreatitis [6]. On the semiological level, there is no difference between acute drug-induced pancreatitis and another [7].

In the most cases, acute drug-induced pancreatitis is presented as an edematous type with a limited progression over time if the suspected drug was suspended [8]. However, in 10 to $15 \%$ of cases, there is an evolution towards severe necrosis of the pancreas with high mortality [7, 9].

Several pathophysiological mechanisms leading to drug-induced pancreatitis have been suggested, including: a hypersensitivity reaction that occurs within four to eight weeks of starting treatment, an accumulation of toxic metabolite that causes pancreatic damage occurring months after the start of treatment, in particular in the case of drugs inducing hypertriglyceridemia (Thiazides, Tamoxifen, Isotretinoin) or even intrinsic activity inducing pancreatic lesions in the case of overdose $[2,10]$.
Tamoxifen exhibits antagonist and agonist activity at estrogen receptors. Its influence on lipid metabolism is determined by its agonist effect $[11,12]$. It stimulates the synthesis and hepatic secretion of very low density lipoproteins (VLDL), which is the main transporter of triglycerides, and which decreases the catabolism of Intermediate Density Lipoproteins (IDL) and Very Low Density Lipoproteins (VLDL), by decreased activity of hepatic lipoprotein lipase and triglyceride lipase, which are key enzymes in the catabolism of triglycerides, and resulting in increased Triglycerides [13, 14].

The main possible mechanism leading to acute tamoxifen-induced pancreatitis is hypertriglyceridemia, with a triglyceride (TG) level higher than $1000 \mathrm{mg} / \mathrm{dl}$ [15]. However, the pathophysiology of pancreatic lesions is not yet clear. Few theories that have been postulated to explain this phenomenon [16], in particular an altered clearance of chylomicrons leading to obstruction of the capillaries, which causes pancreatic ischemia, or pancreatic lipase which hydrolyses excess triglycerides into free fatty acids causing inflammatory changes.

As far as we know, very few cases of acute pancreatitis induced by tamoxifen have been reported in the literature (Table-1). The dose of tamoxifen was 20 $\mathrm{mg} /$ day, except in one patient, whose dose was $10 \mathrm{mg} /$ day. In most cases there was a history of dyslipidemia, however our patient did not have any history of previous dyslipidemia. This suggests that regular blood tests of lipid status are needed in all patients on tamoxifen.

The serum triglyceride level that caused the acute pancreatitis ranged from 900 to $7000 \mathrm{mg} / \mathrm{dl}$. The episode of acute pancreatitis has occurred in the majority of reported cases within 6 months of starting treatment with tamoxifen. The severity also varied in the reported cases, the majority had mild pancreatitis with a favorable evolution like our patient's case, while only one patient had necrotizing pancreatitis.

Table-1

\begin{tabular}{|l|l|l|l|l|l|l|}
\hline Author & $\begin{array}{l}\text { Age } \\
\text { (years) }\end{array}$ & $\begin{array}{l}\text { History of } \\
\text { dyslipidemia }\end{array}$ & Dosage mg/day & $\begin{array}{l}\text { Triglyceridemia } \\
(\mathbf{m g} / \mathbf{d l})\end{array}$ & $\begin{array}{l}\text { Time onset } \\
\text { (months) }\end{array}$ & Evolution \\
\hline Noguchi M et al., 1987 [17] & 34 & Not specified & 20 & 3673 & 7 & Death \\
\hline $\begin{array}{l}\text { Colls BM, George PM } \text { et al., } \\
\text { 1998 [18] }\end{array}$ & 44 & Yes & $\begin{array}{l}\text { Not } \\
\text { Specified }\end{array}$ & 6984 & Not specified & Favorable \\
\hline Elisaf MS et al., 2000 [19] & 53 & Yes & 20 & 5200 & 8 & Favorable \\
\hline Artac M et al., 2002 [3] & 51 & Not specified & 10 & 1344 & 12 & Favorable \\
\hline Lin HH et al., 2004 [19] & 43 & Yes & Not specified & 1040 & 24 & Favorable \\
\hline Alagozlu H et al., 2006 [21] & 46 & Yes & 20 & 900 & 12 & Favorable \\
\hline Sakhri J et al., 2010 [22] & 44 & No & 20 & 1180 & 12 & Favorable \\
\hline $\begin{array}{l}\text { Czyzykowski R } \text { et al., 2014 } \\
{[23]}\end{array}$ & 55 & Yes & 20 & Not specified & 9 & Favorable \\
\hline Kim et al., 2014 [24] & 40 & No & 20 & 3241 & 3 & Favorable \\
\hline Kataria et al., 2017 [2] & 50 & No & 20 & 1050 & 1 & Favorable \\
\hline Tey et al., 2019 [25] & 55 & No & 20 & 3883 & 24 & Favorable \\
\hline Our case $(2020)$ & 42 & No & 20 & $\mathbf{9 5 0}$ & 9 & Favorable \\
\hline
\end{tabular}


Treatment with tamoxifen may alter lipid metabolism, and induce severe pancreatitis, clinicians should consider the possible benefits of its administration and the risk of side effects, especially in patients with a history of dyslipidemia. When hypertriglyceridemia is detected, an appropriate diet and lipid-lowering drug therapy are suggested to reduce the risk of acute pancreatitis induced by hypertriglyceridemia [26].

However, when tamoxifen is suspected to be the etiology of pancreatitis, then it should be interrupted and an alternative treatment should be considered [24, 27].

\section{CONCLUSION}

Acute drug-induced pancreatitis is a rare entity, with a pathophysiology that remains poorly understood.

Since the diagnosis is sometimes difficult, an exhaustive assessment is required before selecting the drug in question, which in this case must be stopped permanently.

Hypertriglyceridemia with tamoxifen remains a little-known complication, seen mainly in dyslipidemic patients or with a family history of dyslipidemia, and in rare cases in normolipid patients. This underlines the interest of checking the lipid profile of each patient during this treatment.

\section{REFERENCES}

1. Odermatt R, Wolfer A, Zaman K. Hormonothérapie dans le cancer du sein: efficacité et effets adverses. Rev Med Suisse. 2013;9:10901094.

2. Kataria PSC, Kendre PP, Patel AA, zoher Bohra M, Tahiliani N. Tamoxifen induced pancreatitis: an unusual complication of commonly used drug. Journal of clinical and diagnostic research: JCDR. 2017;11(8):XD05.

3. Artac M, Sari R, Altunbas H, Karayalcin U. Asymptomatic acute pancreatitis due to tamoxifeninduced severe hypertriglyceridemia in a patient with diabetes mellitus and breast cancer. Journal of chemotherapy. 2002;14(3):309-311.

4. Jones MR, Hall OM, Kaye AM, Kaye AD. DrugInduced Acute Pancreatitis: A Review. 2015;15(1):7.

5. Kaurich T. Drug-induced acute pancreatitis. In: Baylor University Medical Center Proceedings. Taylor \& Francis. 2008 ; 77-81.

6. Rebours V. Acute pancreatitis: an overview of the management. La revue de médecine interne. 2014; 35(10):649-655.

7. Jomli R, Nacef F, Douki S. Pancréatite aiguë induite par l'acide valproïque. L'Encéphale. sept 2013; 39(4):292 5.
8. Blomgren KB, Sundström A, Steineck G, Genell S, Sjöstedt S, Wiholm BE. A Swedish case-control network for studies of drug-induced morbidityacute pancreatitis. European journal of clinical pharmacology. 2002; 58(4):275-283.

9. Slim R, Salem CB, Zamy M, Fathallah N, Raynaud JJ, Bouraoui K, Biour M. Secnidazoleinduced acute pancreatitis: a new side-effect for an old drug?. JOP. Journal of the Pancreas. 2010;11(1):85-6.

10. Badalov N, Baradarian R, Iswara K, Li J, Steinberg W, Tenner S. Drug-induced acute pancreatitis: an evidence-based review. Clinical gastroenterology and hepatology. 2007;5(6):648661.

11. Filippatos TD, Liberopoulos EN, Pavlidis N, Elisaf MS, Mikhailidis DP. Effects of hormonal treatment on lipids in patients with cancer. Cancer Treat Rev. avr 2009; 35(2):175-84.

12. Shapiro CL, Recht A. Side effects of adjuvant treatment of breast cancer. New England Journal of Medicine. 2001;344(26):1997-2008.

13. Hultsch S, Kankainen M, Paavolainen L, Kovanen RM, Ikonen E, Kangaspeska S, Pietiäinen V, Kallioniemi O. Association of tamoxifen resistance and lipid reprogramming in breast cancer. BMC cancer. 2018 Dec 1;18(1):850.

14. Yu Q, Huo J, Zhang Y, Liu K, Cai Y, Xiang T, Jiang Z, Zhang L. Tamoxifen-induced hepatotoxicity via lipid accumulation and inflammation in zebrafish. Chemosphere. 2020 Jan 1;239:124705.

15. Balani AR, Grendell JH. Drug-induced pancreatitis. Drug safety. 2008; 31(10):823-837.

16. Ewald N, Hardt PD, Kloer HU. Severe hypertriglyceridemia and pancreatitis: presentation and management. Current opinion in lipidology. 2009; 20(6):497-504.

17. Noguchi M, Taniya $T$, Tajiri $K$, Miwa $K$, Miyazaki I. Fatal hyperlipaemia in a case of metastatic breast cancer treated by tamoxifen. British journal of surgery. 1987; 74(7):586-587.

18. Colls BM, George PM. Severe hypertriglyceridemia and hypercholesterolaemia associated with tamoxifen use. Clinical Oncology. 1998; 10(4):270-271.

19. Elisaf MS, Nakou K, Liamis G, Pavlidis NA. Tamoxifen-induced severe hypertriglyceridemia and pancreatitis. Annals of oncology. 2000; 11(8):1067-1069.

20. Lin HH, Hsu CH, Chao YC. Tamoxifen-induced severe acute pancreatitis: a case report. Digestive diseases and sciences. 2004; 49(6):997-999.

21. Alagozlu H, Cindoruk M, Unal S. Tamoxifeninduced severe hypertriglyceridemia and acute pancreatitis. Clinical drug investigation. 2006;26(5):297-302.

22. Sakhri J, Salem CB, Harbi H, Fathallah N, Ltaief R. Severe acute pancreatitis due to tamoxifeninduced hypertriglyceridemia with positive 
rechallenge. JOP Journal of the Pancreas. 2010;11(4):382-384.

23. Czyżykowski R, Pollowinczak-Przybyllek J, Janiak A, Herman J, Potemski P. Tamoxifeninduced acute pancreatitis-a case report. Przeglad menopauzalny $=\quad$ Menopause review. 2014;13(1):70.

24. Kim YA, Lee S, Jung JW, Kwon YJ, Lee GB, Shin DG, Park SS, Yun J, Jang YS, Cho DH. Severe acute pancreatitis due to tamoxifen-induced hypertriglyceridemia with diabetes mellitus. Chinese Journal of Cancer Research. 2014 Jun;26(3):341.

25. Tey TT, Maung AC, Lim KW, Hsiang JC. Acute Pancreatitis Caused by Tamoxifen-Induced Severe
Hypertriglyceridemia After 4 Years of Tamoxifen Use. ACG Case Rep J [Internet]. 25 févr 2019 [cité 15 juin 2020];6(2). Disponible sur: https://www.ncbi.nlm.nih.gov/pmc/articles/PMC6 657993/

26. Athyros VG, Giouleme OI, Nikolaidis NL, Vasiliadis TV, Bouloukos VI, Kontopoulos AG, Eugenidis NP. Long-term follow-up of patients with acute hypertriglyceridemia-induced pancreatitis. Journal of clinical gastroenterology. 2002 Apr 1;34(4):472-5.

27. Kochar T, Dhingra P, Kochar A, Sankari M. Tamoxifen-Induced Hypertriglyceridemia-Induced Pancreatitis: A Rare Side Effect: 1395. American Journal of Gastroenterology. 2018; 113:S801. 